\title{
Clinicopathological Characteristics and Survival Analysis of 87 Male Breast Cancer Cases
}

\author{
Tingting Liu Zhongsheng Tong Lihong He Li Zhang
}

Department of Breast Oncology, Key Laboratory of Breast Cancer Prevention and Therapy, Tianjin Medical University Cancer Institute and Hospital / Ministry of Education, Tianjin, China

\section{Keywords}

Male breast cancer - Clinical characteristics - Therapy . Prognosis

\section{Summary}

Background: The aim of this study was to investigate the clinicopathologic characteristics, therapy methods, and prognosis of male breast cancer. Patients and Methods: We retrospectively analyzed the clinicopathological characteristics, recurrence or metastasis, and survival information of 87 male breast cancer patients. Statistical analysis included the Kaplan-Meier method to analyze survivals, log-rank to compare curves between groups, and Cox regression for multivariate prognostic analysis. A $p$ value of $<0.05$ was considered statistically significant. Results: 5-year disease free survival (DFS) and 5-year overall survival (OS) were 66.3 and $77.0 \%$, respectively. Monofactorial analysis showed tumor size, stage, lymph node involvement, and adjuvant chemotherapy to be prognostic factors with regard to 5-year DFS and 5-year OS. Multivariate Cox regression analysis showed tumor size, stage, and adjuvant chemotherapy to be independent prognostic factors with regard to 5-year DFS and 5-year OS. Conclusion: Male breast cancer has a lower incidence rate and poor prognosis. Invasive ductal carcinoma is the main pathologic type. Operation-based combined therapy is the standard care for these patients. Tumor size, stage, and adjuvant chemotherapy are independent prognostic factors. More emphasis should be placed on early diagnosis and early therapy, and adjuvant chemotherapy may improve survival.

\author{
Schlüsselwörter \\ Mammakarzinom des Mannes - Klinische Eigenschaften · \\ Therapie · Prognose
}

\section{Zusammenfassung}

Hintergrund: Ziel dieser Studie war es, die klinisch-pathologischen Eigenschaften, Behandlungsmethoden und Prognose beim Mammakarzinom des Mannes zu untersuchen. Patienten und Methoden: Die klinisch-pathologischen Eigenschaften, das Auftreten von Rezidiven oder Metastasen sowie Informationen bezüglich des Überlebens von 87 männlichen Brustkrebspatienten wurden retrospektiv analysiert. Die Kaplan-Meier-Methode wurde zur statistischen Analyse des Überlebens eingesetzt, der Log-Rank-Test zum Kurvenvergleich zwischen den Gruppen, und die Cox-Regressionsanalyse zur multivariaten Prognoseberechnung. Ein p-Wert von $<0,05$ wurde als statistisch signifikant gewertet. Ergebnisse: Das krankheitsfreie 5-Jahres-Überleben und das 5-Jahres-Gesamtüberleben waren 66,3 bzw. 77,0\%. In der monofaktoriellen Analyse waren Tumorgröße, Stadium, Lymphknotenbefall und adjuvante Chemotherapie Prognosefaktoren hinsichtlich des krankheitsfreien 5-Jahres-Überlebens und des 5-Jahres-Gesamtüberlebens. In der multivariaten Cox-Regressionsanalyse waren Tumorgröße, Stadium und adjuvante Chemotherapie unabhängige Prognosefaktoren hinsichtlich des krankheitsfreien 5-Jahres-Überlebens und des 5-JahresGesamtüberlebens. Schlussfolgerung: Das Mammakarzinom des Mannes hat eine niedrigere Inzidenzrate und eine schlechtere Prognose. Invasive duktale Karzinome sind der häufigste pathologische Subtyp. Eine auf chirurgischer Resektion basierende Kombinationstherapie ist Behandlungsstandard für diese Patienten. Tumorgröße, Stadium und adjuvante Chemotherapie sind unabhängige Prognosefaktoren. Besonderer Wert sollte auf eine frühe Diagnose und Therapie gelegt werden, und adjuvante Chemotherapie könnte einen positiven Einfluss auf das Überleben haben.

\section{KARGER \\ Fax +497614520714 \\ Information@Karger.de}

www.karger.com
(C) 2011 S. Karger GmbH, Freiburg

$1661-3791 / 11 / 0066-0446 \$ 38.00 / 0$

Accessible online at:

www.karger.com/brc
Zhongsheng Tong, MD

Department of Breast Oncology

Tianjin Medical University Cancer Institute and Hospital

Huanhuzhong Road, Hexi District, Tianjin, China

Tel. +86-13920458207, Fax -02223011809

tonghangtt@gmail.com 


\section{Introduction}

Male breast cancer is an uncommon malignancy that accounts for less than $1 \%$ of all cancers in men and less than $1 \%$ of all diagnosed breast cancers [1, 2]. Male and female breast cancers differ in age at diagnosis, histopathologic types, and expression of hormone receptors. The median age at diagnosis in men is 67 years, in contrast to 62 years in women [3, 4]. More than $85 \%$ of all cases are invasive ductal carcinomas (IDC) while in women the frequency of IDC is $70-75 \%$ [5]. In women approximately $60 \%$ of cases are positive for estrogen receptor (ER), whereas in men more than $80 \%$ of specimens are ER-positive [6]. The majority of male breast cancers are also highly positive for the progesterone receptor (PR) [3]. Male breast cancer has not been studied as extensively as female breast cancer. Clinical management of male breast cancer is guided by research on the disease in women or by data from small case reports [7]. Because of its low incidence, a limited number of patients are available for these studies. In this study, we retrospectively investigated the general features, clinicopathologic characteristics, treatments, and outcomes of 87 male breast cancer patients followed at our hospital between 1961 and 2008 .

\section{Patients and Methods}

A total of 87 male patients diagnosed with breast cancer at the Cancer Institute and Hospital of Tianjin Medical University between June 1961 and December 2008 were analyzed retrospectively. Data regarding general patient characteristics (age, presenting signs and symptoms, tumor site and location), histopathology of the primary tumor, treatment modalities (surgery, chemotherapy, radiation, hormone therapy), diseasefree survival (DFS), and overall survival (OS) were obtained by reviewing the medical records. Tumor stage was based on the 6th American Joint Committee on Cancer (AJCC) criteria. Histological type and grading followed the World Health Organization (WHO) classification. 10\% or more of positively stained cells was used as the cut-off for hormonal receptor positivity. Clinical follow-up included history, physical examination, laboratory tests, and radiologic imaging tests every 6-12 months for detection of relapse.

The median age at diagnosis was 58 years (range 26-75 years); $54(62.1 \%)$ patients were diagnosed between the age of 50 and 65 . The most frequent symptom before diagnosis was a mass in the breast, followed by nipple discharge. The tumor was located in the left breast in $52.9 \%$ of the patients and in the right breast in $47.1 \%$ (table 1). Most tumors were located in the central subareolar area $(\mathrm{n}=39) .39(44.8 \%)$ patients had lymph node involvement. All 87 cases were verified by pathological diagnosis. The most frequent histological type was IDC $(\mathrm{n}=69) ; 15(17.2 \%)$ patients had special-type ductal carcinoma, 4 had papillary carcinoma, 6 had mucinous carcinoma, 1 had adenoid cystic carcinoma, 1 had squamous cell carcinoma, 1 had lipid-rich carcinoma, and had malignant fibrous histiocytoma. 58 patients accepted receptor analysis; ER was positive in $50(86.2 \%)$ patients while in $44(75.9 \%)$ patients were PR-positive (39 (67.2\%) patients ER+/PR+; 3 (5.2\%) patients ER-/ PR-; 5 (8.6\%) patients ER-/PR+; 11 (19.0\%) patients ER+/PR-). Moreover, 24 patients accepted human epidermal growth factor receptor 2 (Her-2) analysis; Her-2 was positive in $5(20.8 \%)$ patients, and 2 cases were triple-negative (ER-/PR-/Her-2-). Stage distribution is described in
Table 1. General characteristics of male breast cancer patients $(n=87)$

\begin{tabular}{lc}
\hline Characteristics & Patients, $\mathrm{n}(\%)$ \\
\hline Age, years & $1(1.1)$ \\
20-29 & $3(3.5)$ \\
$30-39$ & $12(13.8)$ \\
$40-49$ & $32(36.8)$ \\
$50-59$ & $28(32.2)$ \\
$60-69$ & $11(12.6)$ \\
$\geq 70$ & \\
Chief complaint & $84(96.6)$ \\
Mass & $2(2.3)$ \\
Nipple discharge & $1(1.1)$ \\
Nipple erosion & $46(52.9)$ \\
Tumor site & $41(47.1)$ \\
Left breast & \\
Right breast & $59(67.8)$ \\
Location of tumor & $8(9.2)$ \\
Retroareolar & $7(8.0)$ \\
Upper outer quadrant & $6(7.0)$ \\
Lower outer quadrant & $7(8.0)$ \\
Upper inner quadrant & \\
Lower inner quadrant & $13(15.0)$ \\
Stage & $24(27.6)$ \\
I & $19(21.8)$ \\
IIA & $15(17.3)$ \\
IIB & $10(11.5)$ \\
IIIA & $3(3.4)$ \\
IIIB & $3(3.4)$ \\
IIIC & $32(36.8)$ \\
TV & $41(47.1)$ \\
2 2 & $14(16.1)$ \\
2-5 5 &
\end{tabular}

table 1. At diagnosis, distant metastasis was present in $3(3.45 \%)$ patients (1 bone metastases, 1 pulmonary metastases, 1 skin metastases).

All patients were surgically treated; 39 (44.8\%) patients received orthodox radical mastectomy. With the continuous improvement of surgical standards, modified radical mastectomy was accepted during the 1990s, and 48 (55.2\%) patients received modified radical mastectomy and axillary curettage. $8(9.2 \%)$ patients received neoadjuvant chemotherapy (3 cases cyclophosphamide/anthracycline/fluorouracil (CAF), 2 cases cyclophosphamide/methotrexate/fluorouracil (CMF), 3 cases paclitaxel/ anthracycline (TA)). After completion of surgery, adjuvant chemotherapy was administered in 56 (64.4\%) cases (18 CMF, 17 CAF, 15 TA, and 6 paclitaxel/anthracycline/cyclophosphamide (TAC)). Radiation therapy was done in 37 (42.5\%) patients with a mean dose of $50 \mathrm{~Gy} .45$ (51.7\%) patients received hormone therapy (41 cases tamoxifen, 4 cases letrozole). Because of this study spanning a long period of time ( $>40$ years), treatment approaches changed in some respect over the years (table 2).

The Kaplan-Meier method was used to estimate DFS and OS. Survival differences were tested using the log-rank test. Hazard ratios, 95\% confidence intervals $(\mathrm{CI})$, and $\mathrm{p}$ values were calculated. A p value less than 0.05 was considered significant. Differentiation of patient characteristics was done by the $\chi^{2}$ test. Statistical analyses were performed by using SPSS 16.0 (SPSS Inc., Chicago, IL, USA) software.

\section{Results}

No patient was lost to follow-up. The median period of follow-up was 59 months (range 2-279 months), and the mean period of follow-up was 73.5 months. Local recurrence was found in $7(8.0 \%)$ patients and metastases in $34(39.1 \%)$ 
Table 2. Therapy about male breast cancer in different decades

\begin{tabular}{|c|c|c|c|c|c|c|}
\hline & \multicolumn{6}{|c|}{ Patients, $\mathrm{n}$} \\
\hline & Total & $\begin{array}{l}1961-1969 \\
(\mathrm{n}=7)\end{array}$ & $\begin{array}{l}1970-1979 \\
(\mathrm{n}=8)\end{array}$ & $\begin{array}{l}1980-1989 \\
(\mathrm{n}=13)\end{array}$ & $\begin{array}{l}1990-1999 \\
(n=20)\end{array}$ & $\begin{array}{l}2000-2008 \\
(\mathrm{n}=39)\end{array}$ \\
\hline \multicolumn{7}{|l|}{ Neoadjuvant chemotherapy } \\
\hline Yes & 8 & 0 & 0 & 1 & 2 & 5 \\
\hline No & 79 & 7 & 8 & 12 & 18 & 34 \\
\hline \multicolumn{7}{|l|}{ Surgical procedure } \\
\hline Radical mastectomy & 39 & 7 & 8 & 13 & 8 & 3 \\
\hline \multicolumn{7}{|l|}{ Adjuvant chemotherapy } \\
\hline Yes & 56 & 3 & 3 & 7 & 12 & 31 \\
\hline No & 31 & 4 & 5 & 6 & 8 & 8 \\
\hline \multicolumn{7}{|l|}{ Radiotherapy } \\
\hline Yes & 37 & 2 & 4 & 5 & 9 & 17 \\
\hline No & 50 & 5 & 4 & 8 & 11 & 22 \\
\hline \multicolumn{7}{|l|}{ Hormone therapy } \\
\hline Yes & 45 & 1 & 2 & 4 & 8 & 30 \\
\hline
\end{tabular}

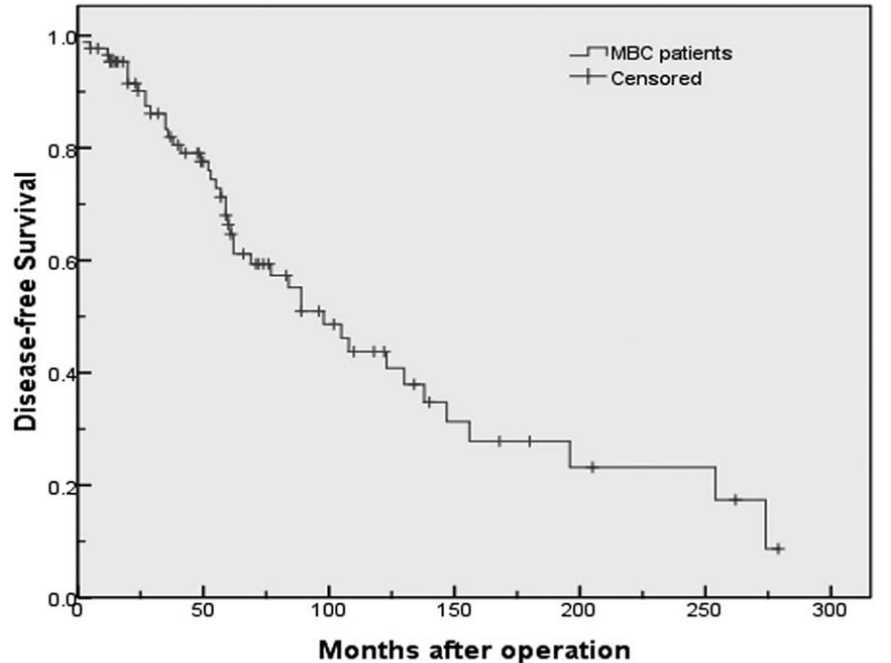

Fig. 1. Disease-free survival curve of male breast cancer (MBC) patients.

patients; 3 of these patients had both local recurrence and metastasis.

5-year DFS and OS were $66.3 \%$ (fig. 1) and $77.0 \%$ (fig. 2), respectively. According to the monofactorial survival analysis, tumor size $(p=0.002)$, stage $(p=0.000)$, lymph node involvement $(\mathrm{p}=0.001)$, and adjuvant chemotherapy $(\mathrm{p}=0.026)$ were statistically significant in terms of 5-year DFS, whereas age, tumor site, surgical procedure, radiotherapy, and hormonal therapy had no significant impact on the 5-year DFS; Moreover, tumor size $(p=0.002)$, stage $(p=0.000)$, lymph node involvement $(\mathrm{p}=0.003)$, and adjuvant chemotherapy $(p=0.022)$ were statistically significant in terms of 5-year OS, whereas age, tumor site, surgical procedure, radiotherapy, and hormonal therapy had no significant impact on the 5-year OS (table 3 ).

In the multivariate Cox regression analysis, tumor size, stage, and adjuvant chemotherapy showed statistical significance in terms of 5-year DFS (table 4) as well as 5-year OS (table 5).

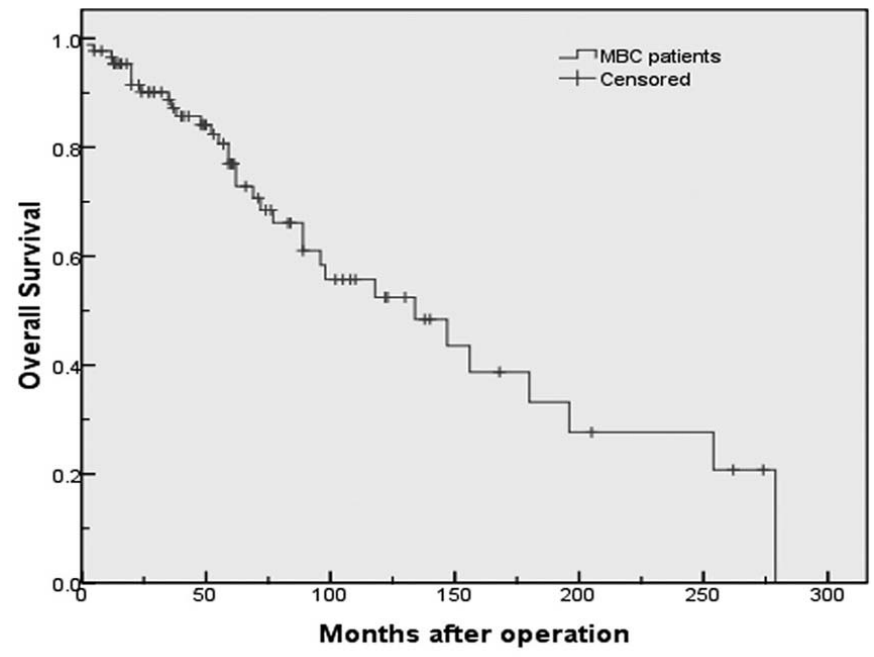

Fig. 2. Overall survival curve of male breast cancer (MBC) patients.

\section{Discussion}

While in women breast cancer is seen more frequently in the post-menopausal period (mean age 62 years), in men it occurs even later at a mean age of 67 years according to the literature [3, 4]. The mean age of our study cohort was 57 years which is lower than in other countries. The etiology of male breast cancer is unclear, however, many factors including hormonal imbalance, and genetic, environmental and epidemiologic factors have been associated with the disease [8]. An imbalance of androgens and estrogens may play an important role; lower testosterone production as found in undescended testes, testicular injury, chronic occupational exposure to heat, orchitis, late puberty, and infertility have been suggested as risk factors [9, 10]. Moreover, previous chest wall irradiation, alcohol consumption, and benign breast conditions such as nipple discharge, breast cysts, and breast trauma may increase the risk of male breast cancer. 
Table 3. Monofactorial analysis of the prognosis of male breast cancer

\begin{tabular}{|c|c|c|c|c|c|c|c|}
\hline Characteristics & $\mathrm{n}$ & 5-year DFS, \% & $\chi^{2}$ & $\mathrm{p}$ & 5 -year OS, \% & $\chi^{2}$ & $\mathrm{p}$ \\
\hline Age & & & 0.562 & 0.453 & & 0.937 & 0.333 \\
\hline$<60$ & 48 & 63.1 & & & 76.8 & & \\
\hline$\geq 60$ & 39 & 70.5 & & & 77.4 & & \\
\hline Tumor site & & & 1.388 & 0.239 & & 0.165 & 0.684 \\
\hline Left breast & 46 & 74.4 & & & 81.6 & & \\
\hline Right breast & 41 & 57.0 & & & 71.6 & & \\
\hline Tumor size & & & 9.209 & $0.002^{\mathrm{b}}$ & & 9.917 & $0.002^{\mathrm{b}}$ \\
\hline$\leq 5 \mathrm{~cm}$ & 73 & 75.8 & & & 85.7 & & \\
\hline$>5 \mathrm{~cm}$ & 14 & 19.5 & & & 28.5 & & \\
\hline Lymph node involvement & & & 11.292 & $0.001^{\mathrm{b}}$ & & 9.015 & $0.003^{b}$ \\
\hline Negative & 48 & 78.5 & & & 86.4 & & \\
\hline Positive & 39 & 52.1 & & & 65.7 & & \\
\hline Stage & & & 40.997 & $0.000^{\mathrm{b}}$ & & 32.688 & $0.000^{\mathrm{b}}$ \\
\hline $\mathrm{I} / \mathrm{II}$ & 56 & 88.2 & & & 90.1 & & \\
\hline III/IV & 31 & 28.0 & & & 50.9 & & \\
\hline Surgical procedure & & & 0.001 & 0.974 & & 1.554 & 0.212 \\
\hline Radical mastectomy & 39 & 69.7 & & & 69.0 & & \\
\hline Modified radical mastectomy & 48 & 64.5 & & & 83.2 & & \\
\hline Adjuvant chemotherapy & & & 4.923 & $0.026^{\mathrm{a}}$ & & 5.207 & $0.022^{\mathrm{a}}$ \\
\hline Yes & 31 & 54.1 & & & 61.8 & & \\
\hline No & 56 & 73.6 & & & 85.5 & & \\
\hline Radiotherapy & & & 0.240 & 0.624 & & 0.109 & 0.741 \\
\hline Yes & 50 & 59.9 & & & 74.7 & & \\
\hline No & 37 & 73.2 & & & 79.2 & & \\
\hline Hormone therapy & & & 3.850 & 0.050 & & 3.565 & 0.059 \\
\hline Yes & 42 & 55.4 & & & 68.1 & & \\
\hline No & 45 & 78.4 & & & 86.3 & & \\
\hline
\end{tabular}

Histopathologic findings in women and men differ due to the fact that the classic lobular structure does not occur in men. As the male breast does not have lobular elements, lobular carcinoma is rare (around 1\%) in men [2]. The most frequent histological type is IDC, accounting for $85-90 \%$ [5]. In our study, IDC was diagnosed in $79.3 \%$ of cases, which is slightly less than reported; no case of lobular carcinoma was found.

ER and PR expression is higher in male breast cancer compared to female breast cancer ( 80 and $60 \%$, respectively) [6, 11]. In our study, receptor analysis was performed in 58 patients, and expression of ER and PR was similar to that reported in the literature. Moreover, until 2003, we extensively developed detection methods for Her-2 in our hospital. Her-2 was detected in only 24 (27.6\%) patients, and less again during the following therapy. Her-2 was not included in the prognostic characteristics analysis because of the limited information regarding Her-2.

Breast cancer in men should be treated with the same strategies as applied in women. Although no consensus has been reached regarding locoregional therapy, the primary therapy is mastectomy with axillary dissection [12]. In previous studies, radical mastectomy was favored based on the rationale that in men the tumors tend to be in close proximity to the pectoralis major muscle and detected at a more advanced stage compared to women [13]. Recent studies are in favor of modified radical or simple mastectomy combined with radiation therapy $[14,15]$. In our study, with case data spanning more than 40 years, 39 cases received radical mastectomy, and 48 patients accepted modified radical mastectomy; no difference was observed in survival.

Although adjuvant chemotherapy and hormonal therapy have proven beneficial to a subgroup of female breast cancer patients, the role of adjuvant chemotherapy in male breast cancer is less clear [16]. However, recent studies reported that adjuvant chemotherapy was beneficial for male breast cancer patients [17]. A decision regarding adjuvant chemotherapy can usually be made by assessing the risks and benefits in the same manner as in female breast cancer patients [11, 17-19]. In our study, $64.4 \%$ of the patients received adjuvant chemotherapy, and the most frequently used chemotherapy regimens were CMF, CAF, and TA. There were significant differences in 5-year DFS and 5-year OS between the group with adjuvant chemotherapy and the group without adjuvant chemotherapy. Because of high hormone receptor expression rates in male breast cancer, adjuvant hormone therapy with tamoxifen is theoretically the rational therapeutic strategy and should be considered in men with breast cancer [11, 1719]. In several retrospective studies, tamoxifen increased DFS and OS in male breast cancer patients $[17,20]$. In our 87 cases, 45 patients received hormone therapy, and their DFS and OS ratios were higher than those of the group that did not receive hormone therapy. However, no difference was seen in the 5 -year DFS/OS between the 2 groups, which may be due to deficits in adjuvant hormone therapy induced by a lack of attention or persistence during hormone therapy. 
Table 4. Multivariate Cox regression analysis of male breast cancer prognosis with regard to disease-free survival

\begin{tabular}{|c|c|c|c|c|c|}
\hline Characteristics & & B Standard error & $\mathrm{p}$ & $\operatorname{Exp}(B)$ & $95 \%$ CI for $\operatorname{Exp}(B)$ \\
\hline Tumor size & 1.014 & 0.401 & $0.011^{\mathrm{a}}$ & 2.756 & $1.256-6.044$ \\
\hline Stage & 1.859 & 0.393 & $0.000^{\mathrm{b}}$ & 6.419 & $2.969-13.880$ \\
\hline Lymph node involvement & 0.652 & 0.347 & 0.060 & 1.919 & $0.973-3.787$ \\
\hline $\begin{array}{l}{ }^{\mathrm{a}} \mathrm{p}<0.05 \\
{ }^{\mathrm{b}} \mathrm{p}<0.01 \\
\mathrm{CI}=\text { Confidence interval. }\end{array}$ & & & & & \\
\hline
\end{tabular}

Table 5. Multivariate Cox regression analysis of male breast cancer prognosis with regard to overall survival

\begin{tabular}{lllll}
\hline Characteristics & $\mathrm{B}$ & Standard error & $\mathrm{p}$ & $\mathrm{Exp}(\mathrm{B})$ \\
\hline Tumor size & 1.334 & 0.469 & $0.004^{\mathrm{a}}$ & 3.798 \\
Stage & 1.993 & 0.472 & $0.000^{\mathrm{a}}$ & 7.337 \\
Lymph node involvement & 0.750 & 0.404 & 0.064 & 2.116 \\
Adjuvant chemotherapy & -1.099 & 0.380 & $0.004^{\mathrm{a}}$ & 0.333 \\
\hline${ }^{\mathrm{a}} \mathrm{p}<0.01$. & & & $0.958-4.672$ \\
$\mathrm{CI}=$ Confidence interval. & & & \\
\hline
\end{tabular}

Postoperative radiotherapy does achieve local control, but no effects have been observed on survival [21]. In men treated with mastectomy, adjuvant radiotherapy has been shown to decrease local recurrence. Whether or not radiotherapy is indicated depends on local findings [22, 23]. Radiotherapy is performed in tumors involving the skin and chest wall. Involvement of the skin and nipples is more frequent in men than in women, which may be related to breast size and proximity of the tumor to these structures [24]. In our study, $37(42.5 \%)$ patients received postoperative radiotherapy, and no significant difference was seen between the group receiving radiotherapy and that not receiving radiotherapy. The similar survival rates may be seen as an indication of a contribution of radiotherapy to DFS and OS.

Consensus has been reached that larger tumors confer a poor prognosis [8]. Guinee et al. [24] in their study comprising 335 cases showed that clinical axillary lymph node involvement as well as clinical tumor size had an influence on prognosis. In our study, univariate analysis of 5-year DFS and OS showed tumor size and lymph node involvement to have a significant effect on survival, and multivariate analysis of 5-year DFS showed tumor size to cause significant differences in survival (table 3).

Traditionally, the lifespan of men with breast cancer was thought to be shorter than that of female breast cancer patients $[3,25]$. While some investigators explain this with a more aggressive biologic behavior of male breast cancer, the more common explanation is the rareness of male breast cancer resulting in diagnosis at a more advanced stage and non-standard therapy compared to women with breast carcinoma. However, recent studies report that if male breast cancer patients are matched for prognostic factors such as age and TNM stage, the clinical outcome is similar [26, 27].

In conclusion, male breast cancer is an uncommon disease. Our study showed that tumor size, stage, lymph node involvement, adjuvant chemotherapy, and recurrence or metastasis had a significant effect on survival; stage was the most important prognosis factor with regard to both DFS and OS. Public awareness of the disease should be improved and an appropriate system for early detection and adequate treatment strategies implemented. Moreover, men presenting with breast symptoms should be examined in the same manner as women to facilitate early detection and better treatment outcomes.

\section{Disclosure Statement}

The authors declare no conflict of interest.

\section{References}

1 Jemal A, Siegel R, Ward E, Hao Y, Xu J, Thun MJ: Cancer statistics, 2009. CA Cancer J Clin 2009; 59:225-249.

2 Jemal A, Thomas A, Murray T, Thun M: Cancer statistics 2002. CA Cancer J Clin 2002;52:23-47.

$\checkmark 3$ Giordano SH, Cohen DS, Buzdar AU, Perkins G, Hortobagyi GN: Breast carcinoma in men: a population-based study. Cancer 2004;101:51-57.
4 Anderson WF: The descriptive epidemiology of male versus female breast cancer, using age-period-cohort (APC) models. ASCO Breast Cancer Symposium2008; abstr 93.

5 Scott-Conner CE, Jochimsen PR, Menck HR, Winchester DJ: An analysis of male and female breast cancer treatment and survival among demographically identical pairs of patients. Surgery 1999;126:775-780.
6 Meijer-van Gelder ME, Look MP, Bolt-de Vries J, Peters HA, Klijn JG, Foekens JA: Clinical relevance of biologic factors in male breast cancer. Breast Cancer Res Treat 2001;68:249-260.

7 Cutuli B: Strategies in treating male breast cancer. Expert Opin Pharmacother 2007;8:193-202.

8 Giordano SH: A review of the diagnosis and management of male breast cancer. Oncologist 2005;10:471-479. 
9 Medras M, Filus A, Jozkow P, Winowski J, Sicinska-Werner T: Breast cancer and long-term hormonal treatment of male hypogonadism. Breast Cancer Res Treat 2006;96:263-265.

10 Hirose Y, Sasa M, Bando Y, Hirose T, Morimoto T, Kurokawa Y, Nagao T, Tangoku A: Bilateral male breast cancer with male potential hypogonadism. World J Surg Oncol 2007;5:60.

11 Agrawal A, Ayantunde AA, Rampaul R, Robertson JF: Male breast cancer: a review of clinical management. Breast Cancer Res Treat 2007;103:11-21.

12 De Perrot M, Deleaval J, Robert J, Spiliopoulos A: Thirty year experience of surgery for breast carcinoma in men. Eur J Surg 2000;166:929-931.

13 Borgen PI, Wong GY, Vlamis V, Potter C, Hoffmann B, Kine DW, Osborne MP, McKinnon WM: Current management of male breast cancer: a review of 104 cases. Ann Surg 1992;215:451-459.

14 Golshan M, Rusby J, Dominguez F, Smith BL: Breast conservation for male breast carcinoma. Breast 2007;16:653-656.

15 Comet B, Cutuli B, Penault-Llorca F, Bonneterre J, et al.: Male breast cancer: a review. Bull Cancer 2009;96:181-189.

16 Giordano SH, Buzdar AU, Hortobagyi GN: Breast cancer in men. Ann Intern Med 2002;137:678-687.

17 Giordano SH, Perkins GH, Broglio K, et al.: Adjuvant systemic therapy for male breast carcinoma. Cancer 2005;104:2359-2364.

18 Nahleh Z, Girnius S: Male breast cancer: a gender issue. Nat Clin Pract Oncol 2006;3:428-437.

19 Fentiman IS, Fourquet A, Hortobagyi GN: Male breast cancer. Lancet 2006; 367:595-604.

20 Ribeiro GG, Swindell R, Harris M, Banerjee SS, Cramer A: A review of the management of the male breast carcinoma based on an analysis of 420 treated cases. Breast 1996;5:141-146.

21 Atahan L, Yildiz F, Selek U, Sari S, Gurkaynak M: Postoperative radiotherapy in the treatment of male breast carcinoma: a single institute experience. J Nat Med Assoc 2006;98:559-563.

22 Belkacémi Y, Penault-Llorca F, Gligorov J, Azria D: Intérêt des classifications moléculaires pour prédire la récidive locale et la rechute métastatique des cancers du sein. Cancer Radiother 2008;12:577-583.

23 Hennequin C, Romestaing P, Maylin C: Irradiation des aires ganglionnaires dans le cancer du sein. Cancer Radiother 2008;12:559-564.

24 GuineeVF, Olsson H, Moller T, Shallenberger RC, van den Blink JW, Peter Z, et al.: The prognosis of the breast cancer in male. A report of 335 cases. Cancer 1993;71:154-161.

25 Yildirim E, Berberoglu U: Male breast cancer: a 22-year experience. Eur J Surg Oncol 1998;24:548-552.

26 Park S, Kim JH, Koo J, et al.: Clinicopathological characteristics of male breast cancer. Yonsei Med J 2008;49:978-986.

27 Botan RD, Alvares MN, Hassan A: Male breast cancer: prognostic factors evaluation in a 35-year service. J Clin Oncol 2009;27(suppl):abstr 1618. 